\begin{tabular}{l|l|l|}
\cline { 3 - 3 } CRITICAL & $\begin{array}{l}\text { Western Ghats } \\
\text { EARTNERSHIP FUND }\end{array}$ \\
Special Series
\end{tabular}

\title{
Discovery and first description of male Cnemaspis heteropholis Bauer, 2002 (Reptilia: Gekkonidae) from Agumbe, central Western Ghats, India
}

\author{
S.R. Ganesh ${ }^{1}$, Rachakonda Sreekar ${ }^{2}$, Saunak P. Pal ${ }^{3}$, Gautam Ramchandra ${ }^{4}$, C. Srinivasulu ${ }^{5} \&$ \\ Bhargavi Srinivasulu ${ }^{6}$
}

\author{
1,2,4 Agumbe Rainforest Research Station, Agumbe, Shimoga, Karnataka 577411, India \\ ${ }^{1}$ Chennai Snake Park, Chennai, Tamil Nadu 600022, India \\ ${ }^{2}$ Biodiversity Research and Conservation Society, G4, MRK Towers, Swarnadhamanagar, Old Bowenpally, Secunderabad, Andhra \\ Pradesh 500011, India \\ ${ }^{3}$ Centre for Ecological Sciences, Indian Institute of Science, Bengaluru, Karnataka 560012, India \\ ${ }^{5,6}$ Wildlife Biology Section, Department of Zoology, University College of Science, Osmania University, Hyderabad, Andhra Pradesh \\ 500007, India
}

Email: ${ }^{1}$ snakeranglerr@gmail.com, ${ }^{2}$ sreekar1988@gmail.com, ${ }^{3}$ herps.saunak@gmail.com, ${ }^{4}$ gautham1112@gmail.com,

${ }^{5}$ hyd2masawa@gmail.com (corresponding author), ${ }^{6}$ bharisrini@gmail.com

Cnemaspis Strauch, 1887 is one of the most speciose paleotropical gekkonid genera with around 100 recognised species (Smith 1935). In India, Cnemaspis species are recorded from the hilly regions of southern India and from northeastern India (Smith

Date of publication (online): 26 August 2011

Date of publication (print): 26 August 2011

ISSN 0974-7907 (online) | 0974-7893 (print)

Editor: Aaron Bauer

\section{Manuscript details:}

Ms \# 02614

Received 25 October 2010

Final received 13 June 2011

Finally accepted 01 August 2011

Citation: Ganesh, S.R., R. Sreekar, S.P. Pal, G. Ramchandra, C. Srinivasulu \& B. Srinivasulu (2011). Discovery and first description of male Cnemaspis heteropholis Bauer, 2002 (Reptilia: Gekkonidae) from Agumbe, central Western Ghats, India. Journal of Threatened Taxa 3(8): 2023-2027.

Copyright: @ S.R. Ganesh, Rachakonda Sreekar, Saunak P. Pal, Gautam Ramchandra, C. Srinivasulu \& Bhargavi Srinivasulu 2011. Creative Commons Attribution 3.0 Unported License. JoTT allows unrestricted use of this article in any medium for non-profit purposes, reproduction and distribution by providing adequate credit to the authors and the source of publication.

Acknowledgements: We acknowledge The Gerry Martin Project for financial support. We thank Karnataka Forest Department for permission; Romulus Whitaker, Gowri Shankar, Gerry Martin and colleagues at the Agumbe Rainforest Research Station for their support and encouragement the Head, Osmania University, Hyderabad and Chennai Snake Park for encouragement and facilities. This paper is part of CEPF-funded Reptile Assessment of the Western Ghats Project and we duly acknowledge the help from CEPF for publication of this article. We thank anonymous referees for comments on an earlier draft of the manuscript.

OPEN ACCESS | FREE DOWNLOAD () (1) (10)
Abstract: Cnemaspis heteropholis Bauer, 2002 was hitherto defined based only on its holotype, an adult female collected from Gund hill range, Western Ghats, India. Recently we observed adult male and juvenile specimens of this species at Agumbe, ca. $200 \mathrm{~km}$ south of its type locality and consequently we recharacterize and expand the definition of this species by providing information about intraspecific variation based on the new specimens. Colouration in life and natural history data are also provided.

Keywords: Agumbe, Cnemaspis heteropholis, expanded characterization, juvenile, male, natural history, pores.

1935; Sharma 2002). From Karnataka eight species of Cnemaspis - C. heteropholis Bauer, 2002, C. indica (Gray, 1846), C. indraneildasii Bauer, 2002, C. jerdoni (Theobald, 1868), C. littoralis (Jerdon, 1854), C. mysoriensis (Jerdon, 1853), C. ornata (Beddome, 1870) and C. tropidogaster sensu Smith, (1935) (Boulenger, 1885) - have been reported (Smith 1935; Bauer 2002; Biswas 2006; Ganesh et al. 2007; Manamendra-Arachchi et al. 2007). C. tropidogaster sensu stricto is currently believed to be a Sri Lankan

This article forms part of a special series on the Western Ghats of India disseminating the results of work supported by the Critical Ecosystem Partnership Fund (CEPF), a joint initiative of l'Agence Française de Développement, Conservation International, the Global Environment Facility, the Government of Japan, the MacArthur Foundation and the World Bank. A fundamental goal of CEPF is to ensure civil society is engaged in biodiversity conservation. Implementation of the CEPF investment program in the Western Ghats is led and coordinated by the Ashoka Trust for Research in Ecology and the Environment (ATREE). 


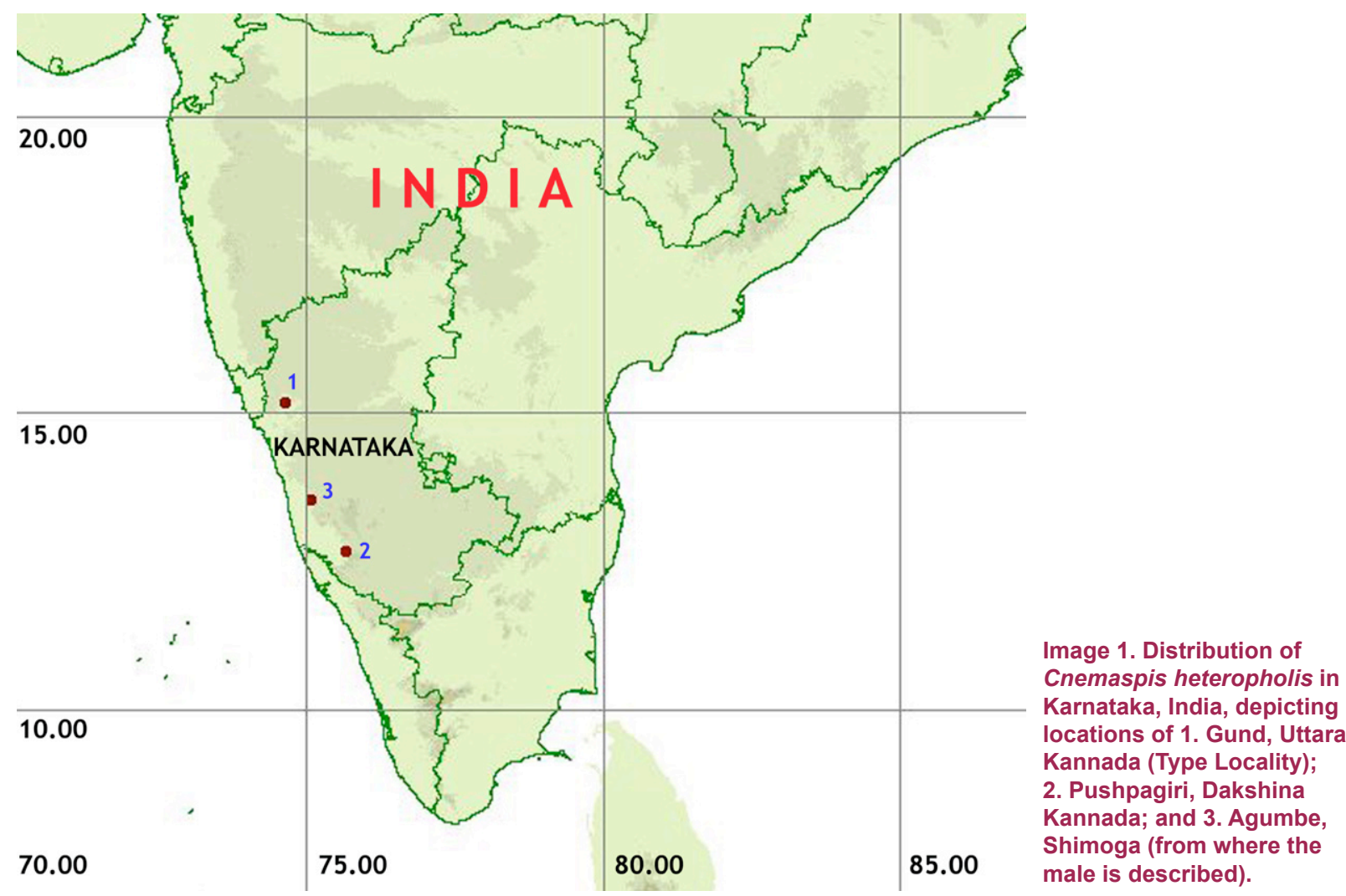

endemic species known only from the type specimens and $C$. littoralis (type lost) is treated as incertae sedis (Manamendra-Arachchi et al. 2007).

Bauer (2002) described Cnemaspis heteropholis based only on the holotype ZMH R06158 (Zoologisches Museum Hamburg, Germany), an adult female, $40.19 \mathrm{~mm}$ long, collected by G.A. von Maydell, on 20 January 1956 from Gund [hill range] $\left(15^{\circ} 15^{\prime} \mathrm{N} \&\right.$ 74036'E; 480m elevation), Uttara Kannada District, Karnataka State, Western Ghats, India (Image 1). Subsequently, Biswas (2006) observed this species in Pushpagiri $\left(12^{\circ} 40^{\prime} \mathrm{N} \& 7^{\circ} 39^{\prime} \mathrm{E}\right.$; $833 \mathrm{~m}$ ), a locality that is ca. $500 \mathrm{~km}$ south of the type locality (Image 1). Unfortunately, no morphological data of the individuals appeared in his work, therefore this species is still relatively poorly characterized. Bauer (2002) remarked "Comparisons of Cnemaspis indraneildasii and $C$. heteropholis are hindered by the fact that only females are known for the two new species. The condition of preanal and femoral pores, useful diagnostic characters that are present only in the males in this genus (Smith 1935), are thus unknown. The absence of the male also hinders the interpretations of the possible affinities of the new species". The present
Table 1. Measurements (in $\mathrm{mm}$ ) of the four newly documented individuals, arranged in increasing size and identified by their maturity, sex and year of sighting. '-' indicates non availability of data; '?' indicates missing part of the tail.

\begin{tabular}{|c|c|c|c|c|}
\hline Characters & $\begin{array}{c}\text { Juvenile 1 } \\
\text { (yr. 2008) }\end{array}$ & $\begin{array}{c}\text { Juvenile 2 } \\
\text { (yr. 2010) } \\
\text { CESL 097 }\end{array}$ & $\begin{array}{c}\text { Adult } \\
\text { male 2 } \\
\text { (yr. 2010) }\end{array}$ & $\begin{array}{c}\text { Adult } \\
\text { male 1 } \\
\text { (yr. 2008) }\end{array}$ \\
\hline SVL & 18.2 & 28.0 & 44.3 & 45.1 \\
\hline TL & 19.8 & $19.86+?$ & 41.2 & 47.1 \\
\hline BW & - & 4.38 & 9.75 & - \\
\hline HL & 8.9 & 9.26 & 13.1 & 14.0 \\
\hline HW & 5.1 & 5.12 & 8.2 & 7.6 \\
\hline HD & 3.2 & 2.82 & - & 5.9 \\
\hline ED & 1.6 & 1.34 & 3.45 & 3.1 \\
\hline EL & - & 0.77 & 1.5 & - \\
\hline E-E & 1.4 & 2.70 & 3.6 & 3.3 \\
\hline E-S & 3.0 & 4.02 & 6.0 & 7.2 \\
\hline IN & 0.8 & 1.28 & 1.7 & 2.1 \\
\hline IO & 2.0 & 2.97 & 4.8 & 4.7 \\
\hline A-G & 9.8 & 12.09 & 19.5 & 20.2 \\
\hline UAL & 3.5 & 2.83 & - & 8.5 \\
\hline LAL & 3.7 & 4.85 & - & 8.8 \\
\hline FEL & 4.8 & 5.03 & - & 11.2 \\
\hline TBL & 4.3 & 4.22 & - & 9.1 \\
\hline & & & & \\
\hline
\end{tabular}


communication expands the external morphological characterization of this poorly known, endemic species by providing intraspecific variations from male conspecifics observed in Agumbe, Karnataka, Western Ghats, India.

\section{Materials and Methods}

Our observations are based on two live adult males and two juvenile $C$. heteropholis sighted in the wild by the first four authors in Agumbe $\left(13^{0} 50^{\prime} \mathrm{N} \& 75^{\circ} 09^{\prime} \mathrm{E}\right.$; $557 \mathrm{~m}$ ) (Image 1) Karnataka State, Western Ghats, India on 02 May 2008, 12 November 2008, 05 May 2010 and 09 July 2010. These live individuals were examined, photographed in life in situ and released (Table 1). Only one voucher specimen (CESL 097) was collected by the third author (SP) and deposited in the collection of the Centre for Ecological Sciences, Indian Institute of Science, Bengaluru, India. All measurements were recorded using a slide vernier calliper and are given to the nearest $0.1 \mathrm{~mm}$. Morphometric abbreviations are as follows: SVL, snout to vent length; TL, tail length; BW, maximum body width; HL, head length from posterior axis of the jaw to the tip of the snout; HW, head width at its widest point; HD, head depth at its parietal region; ED, horizontal eye diameter; EL, maximum ear diameter; E-E, distance from posterior edge of eye to anterior edge of ear; E-S, anterior edge of eye to snout tip; IN, internarial distance; IO, transverse distance between anterior most supraciliaries; LAL, lower-arm length measured as distance from elbow to wrist; UAL, upper-arm length measured as distance between axilla and angle of elbow; FEL, femur length measured as distance between groin and knee; TBL, tibia length measured as distance between knee and heel; and A-G, axilla to groin distance. Sex was determined on the basis of the presence of enlarged hemipenal bulges and femoral pores.

\section{Observations}

\section{Cnemaspis heteropholis Bauer, 2002}

Description: Snout-vent length 18.2-45.1 mm. Head oblong, large (HL/SVL ratio 0.33), wide (HW/ SVL ratio 0.19) and distinct from neck. Snout long (E-S/HW ratio 0.77), much longer than eye-diameter (ED/E-S ratio 0.46). Scales on the canthus-rostralis larger than the scales on the forehead and dorsum. Eye small (ED/HL ratio 0.20). Ear-opening oval and small (EL/HL ratio 0.09). Eye-ear distance slightly larger than eye diameter (EE/ED ratio 1.16). Rostral wide as long, completely divided by the rostral groove. Nostrils oval, not in contact with the first supralabial, three postnasals. Mental enlarged, triangular, longer and wider than rostral; the first pair of postmentals separated by three enlarged scales (Image 2d); outer postmentals smaller than the inner. Supralabials to the angle of jaws 9 , infralabials to the angle of jaws 8 (Image 2c). Body relatively wide (BW/SVL ratio 0.11 ) not elongate (A-G/SVL ratio 0.45 ), ventro-lateral fold absent. Six femoral pores on either side separated by $16-18$ non pore-baring scales (Image $2 b$ ). Porebearing scale enlarged relative to the adjacent scales. Original as well as regenerated tail oval in crosssection, almost equal to snout-vent length (TL/SVL ratio 0.95). No enlarged post-cloacal spurs. Scales on post-cloacal region slightly larger than those on the rest of the dorsum of the tail. Upper arm slightly shorter than lower arm (UAL/LAL ratio 0.95). Femur shorter than tibia (FEL/TBL ratio 1.17).

Colour in life: Dorsum of head, limbs and vertebral region mottled light brown with dark blotches along the dorsal midline larger than those on the head, either side of this dorsal midline are an additional dorsolateral row of light brown spots. Flanks dark brown with light yellow spots (tubercles; Image 2). Digits with alternating white and black bands, white at joints. Original and regenerated tail brown with dark spots. Throat buff interspersed with yellow, unpigmented abdomen and bright yellow on the scales between the femoral pores. Two yellowish-white stripes on the dorsolateral side of the head from the rostrum to the eye, and three stripes running after the eye to the ear.

Difference between the sexes: No variation in meristic characters was observed among the sexes except for the presence of six femoral pores on either side in males. Though there are variations in the measurements between the sexes, they should be treated with caution as a live specimen is being compared with a preserved specimen. Shrinkage commonly occurs in geckos following fixation and preservation.

Natural History: During May 2008, a juvenile was observed at $1630 \mathrm{hr}$ on a drying stream-bed, among moss-clad rocks, carpeted with thick leaf litter. During October 2008, an adult male was observed at $1120 \mathrm{hr}$ inside the upper arch of a small cave within a forest patch. Several $(n>5)$ individuals were sighted 


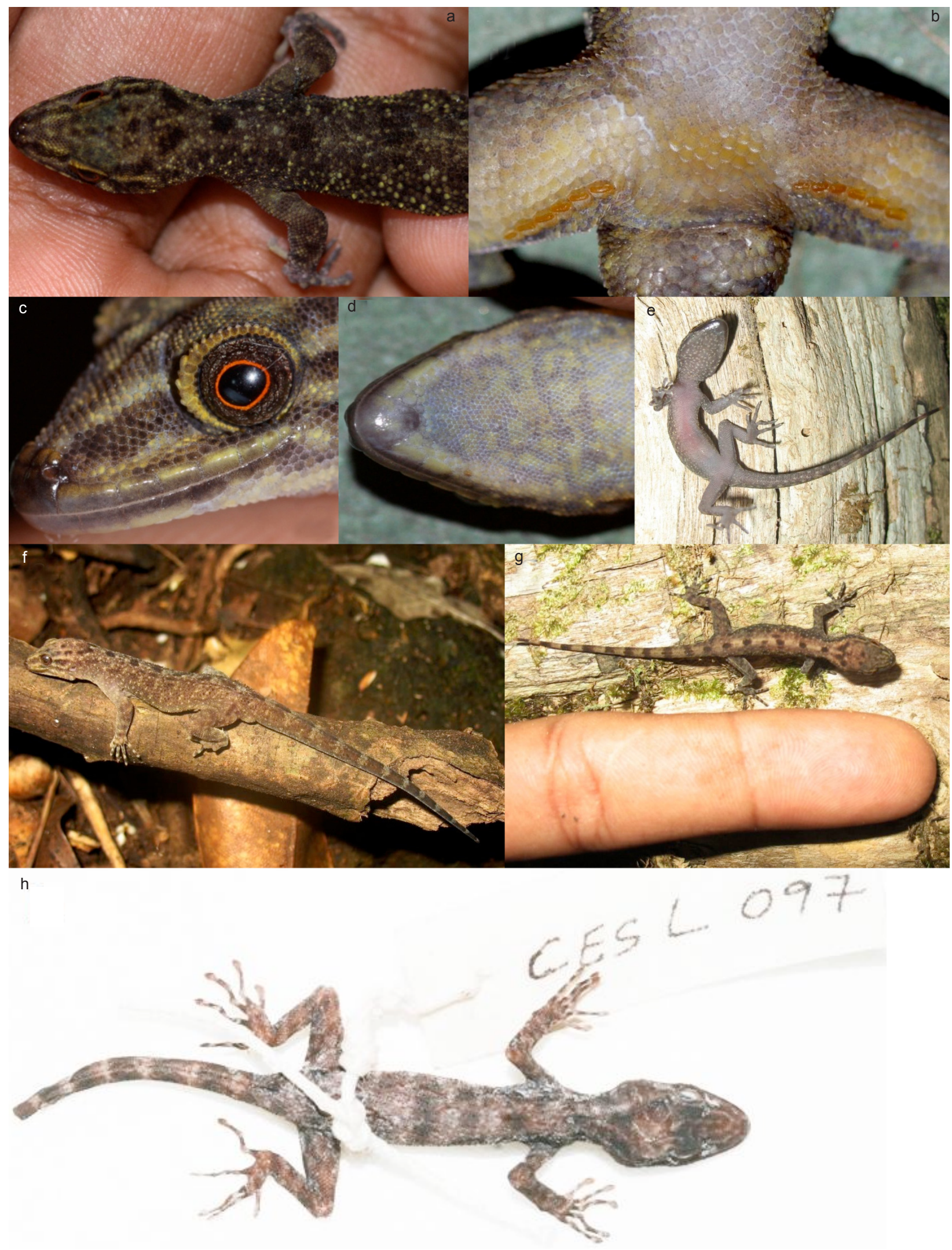

Image 2. Cnemaspis heteropholis adult male.

a - dorsal view; b - portraying the number of femoral pores; $c$ - head profile; $d$ - gular; e - venter (juvenile); $f$ - entire - adult male; $g$ - entire - juvenile; $\mathbf{h}$ - preserved juvenile specimen with incomplete tail. 
together and darted inside small crevices at the least sign of our approach. During May 2010, an adult male was found resting on a mesh fence in the Agumbe Rainforest Research Station at 2100hr. Opportunistic sightings since 2008 suggest that the lizard is not common and is somewhat crepuscular in habit and were observed foraging in the night. Other lizard species found syntopic were Hemidactylus cf. brookii, Hemidactylus frenatus, Ristella beddomii, Calotes rouxii and Cnemaspis indraneildasii.

Comparisons: Presence of six femoral pores on each side and the absence of preanal pores distinguish C. heteropholis from C. boiei (Gray, 1842), C. ornata (Beddome, 1870), C. beddomei (Theobald, 1876), C. littoralis (Jerdon, 1853), C. otai Das \& Bauer, 2000, C. nairi Inger et al., 1984 and C. australis ManamendraArachchi et al., 2007; absence of spine-like tubercles on flanks distinguishes it from the newly described $C$. nilagarica Manamendra-Arachchi et al., 2007 and $C$. monticola Manamendra-Arachchi et al., 2007. It may be distinguished from the morphologically similar $C$. sisparensis (Theobald, 1876) by its heterogenous (vs. homogenous) dorsal scalation and the presence of six femoral pores on each side (vs. 7-8) and C. wynadensis (Beddome, 1870) from having three (vs. 1-2) scales between the enlarged postmentals, weakly conical (vs. keeled) dorsal head scales and subcaudals on median series divided.

\section{Discussion}

Our specimens are consistent with the original description of Bauer (2002) in morphology and colour. J.C. Daniel collected " $C$. wynadensis" from the current locality in 1965 (CAS 104211, Herpetology collection catalogue, California Academy of Sciences). The specific epithet "wynadensis" refers to its original collection locality in Wynaad District, Kerala State and its surrounding localities (Smith 1935; Bauer 2002) and there have been no other records of it occurring in Karnataka. It might be possible that this specimen might actually be a $C$. heteropholis misidentified as $C$. wynadensis due to external morphological similarities and that $C$. heteropholis has been described only in the recent past. This explains the cause as to why this species has remained relatively obscure. Biswas'(2006) record from Pushpagiri reveals that this species occurs further south and in potential sympatry with several, morphologically similar-looking congeners like $C$. wynadensis and C. sisparensis. But nonetheless, its unique, intermixed, prominent large tuberculate dorsal scalation clearly gives away this species. It is likely that $C$. heteropholis occupies a wide range of biotopes between the Palghat and the Goa gaps in the Western Ghats, at altitudes ranging from $480 \mathrm{~m}$ (Bauer 2002) to up to $833 \mathrm{~m}$ (Biswas 2006). More sightings are needed to better understand its characterization, distribution and biology.

\section{REFERENCES}

Bauer, A.M. (2002). Two new species of Cnemaspis (Reptilia: Squamata: Gekkonidae) from Gund, Uttara Kannada, India. Mitteilungen aus dem Hamburgischen Zoologischen Museum und Institut 99: 155-167.

Biswas, S. (2006). A possible occurrence of regional integumentary loss in Cnemaspis heteropholis from southern India. Gekko 5(2): 28-30.

Ganesh, S.R., S.R.C. Mouli \& S.L. Edward (2007). A study on herpetofaunal assemblages in the rain forests of Western Ghats, Karnataka, India. Journal of Scientific Transactions in Environment and Technovation 1(2): 95-103.

Manamendra-Arachchi, K., S. Batuwita \& R. Pethiyagoda (2007). A taxonomic revision of the Sri Lankan day-geckos (Reptilia: Gekkonidae: Cnemaspis), with description of new species from Sri Lanka and southern India. Zeylanica 7 (1): 9-122.

Sharma, R.C. (2002). Fauna of India, Reptilia - Volume II, Sauria. Zoological Survey of India, Calcutta, 430pp.

Smith, M.A. (1935). Fauna of British India including Ceylon and Burma. Reptilia and Amphibia - Volume II, Sauria. Today and Tomorrow's Printers \& Publishers, New Delhi, Indian Reprint 1974, 440pp. 